(c) American Dairy Science Association, 2003.

\title{
Factors Associated with the Likelihood of Giardia spp. and Cryptosporidium spp. in Soil from Dairy Farms ${ }^{1}$
}

\author{
R. S. Barwick, ${ }^{\star}$ H. O. Mohammed, ${ }^{\star}$ M. E. White, ${ }^{\star}$ and R. B. Bryant \\ *Department of Population Medicine and Diagnostic Sciences, College of Veterinary Medicine, Cornell University, Ithaca, NY 14853, USA \\ fDepartment of Soil, Crops, and Atmospheric Sciences, Cornell University, Ithaca, NY 14853, USA
}

\begin{abstract}
A study was conducted to identify factors associated with the likelihood of detecting Giardia spp. and Cryptosporidium spp. in the soil of dairy farms in a watershed area. A total of 37 farms were visited, and 782 soil samples were collected from targeted areas on these farms. The samples were analyzed for the presence of Cryptosporidium spp. oocysts, Giardia spp. cysts, percent moisture content, and $\mathrm{pH}$. Logistic regression analysis was used to identify risk factors associated with the likelihood of the presence of these organisms. The use of the land at the sampling site was associated with the likelihood of environmental contamination with Cryptosporidium spp. Barn cleaner equipment area and agricultural fields were associated with increased likelihood of environmental contamination with Cryptosporidium spp. The risk of environmental contamination decreased with the $\mathrm{pH}$ of the soil and with the score of the potential likelihood of Cryptosporidium spp. The size of the sampling site, as determined by the sampling design, in square feet, was associated nonlinearly with the risk of detecting Cryptosporidium spp. The likelihood of the Giardia cyst in the soil increased with the prevalence of Giardia spp. in animals (i.e., 18 to 39\%). As the size of the farm increased, there was decreased risk of Giardia spp. in the soil, and sampling sites which were covered with brush or bare soil showed a decrease in likelihood of detecting Giardia spp. when compared to land which had managed grass. The number of cattle on the farm less than 6 mo of age was negatively associated with the risk of detecting Giardia spp. in the soil, and the percent moisture content was positively associated with the risk of detecting Giardia spp. Our study showed that these two protozoan exist in dairy farm
\end{abstract}

\footnotetext{
Received August 27, 2002.

Accepted November 3, 2002.

Corresponding author: H. O. Mohammed; e-mail: hom1@ cornell.edu.

${ }^{1}$ Supported partially by grants from the USDA Formula Funds, New York State Department of Environmental Protection, The Watershed Agricultural Council, and the Water Resources Institute, Cornell University.
}

soil at different rates, and this risk could be modified by manipulating the $\mathrm{pH}$ of the soil.

(Key words: risk, Cryptosporidium spp., Giardia spp., soil)

\section{Abbreviation key: $\mathbf{O R}=$ odd ratio. \\ INTRODUCTION}

Cryptosporidium spp. and Giardia lamblia are the two parasites responsible for causing the gastrointestinal disorders of cryptosporidiosis and giardiasis, respectively (Fayer, 1997). Both diseases are characterized by severe gastroenteritis and diarrhea, and symptoms may include diarrhea, abdominal pain, and even fever and vomiting (Fayer, 1997). The organisms can be transmitted through water and have been found to be prevalent in unfinished water sources (Madore et al., 1987; LeChavallier et al., 1991; Rose et al., 1991; Roach et al., 1993). Both organisms can survive modern drinking water treatments and have been implicated in several drinking water outbreaks throughout the world, including North America and the United Kingdom (Hayes et al., 1989; Smith et al., 1989; Joseph et al., 1991; Richardson et al., 1991; Rose et al., 1991; Leland et al., 1993; MacKenzie et al., 1995; Goldstein et al., 1996; Solo-Gabriele and Neumeister, 1996).

Cryptosporidiosis is transmitted by the ingestion of an infective oocyst which is shed through the feces of other infected hosts (Fayer, 1997). Cryptosporidium parvum and Cryptosporidium muris are the species most commonly associated with infection in humans and other mammals (Fayer, 1997). Cryptosporidium spp. has been found to be prevalent in mammals such as sheep, horses, goats, pigs, dogs, cats, and cattle (Anderson, 1991; Moore and Zeman, 1991; Mtambo et al., 1991; Xiao et al., 1993; Garber et al., 1994; Xiao and Herd, 1994; Atwill et al., 1997; Johnson et al., 1997; Muriuki et al., 1997; Olson et al., 1997; Wade et al., 2000). Through excretion and the process of manure spreading on farmland, these populations contaminate the environment. By contaminating the environment, dairy farms serve as a potential source of exposure of the human population to Cryptosporidium spp (Smith and Rose, 1998). 
Like Cryptosporidium, Giardia is spread through the fecal-oral route, with the ingestion of Giardia cysts that can infect the small intestine of mammals. The organism reproduces in the host, and infective cysts are shed into the environment through the feces (Buret et al., 1990). Giardia has been found to be prevalent in bovine populations (Buret et al., 1990; Xiao and Herd, 1994; Olson et al., 1997) and, like Cryptosporidium spp., it is these populations that may serve as a source of contamination to water supplies as Giardia cysts travel through the environment.

Most of the research on these two organisms in the environment has focused on their presence in water sources (Madore et al., 1987; LeChavallier et al., 1991; Roach et al., 1993). However, the route of transmission of the Cryptosporidium oocyst or the Giardia cyst from the animal source to the water supply system through the environment must be determined in order to implement control strategies and ultimately prevent contamination of public water supplies. It has already been demonstrated experimentally that Cryptosporidium oocysts are able to move through various soil types (Mawdsley et al., 1996a) and resist environmental pressures such as temperature and $\mathrm{pH}$, indicating its potential to contaminate and survive in the environment (Fayer and Leek, 1984; Robertson et al., 1992; Brown et al., 1996; Fayer and Nerad, 1996). Due to the ubiquitous nature of these organisms, an important step in the risk assessment framework for the protection of water quality is determining whether these two parasites are present in the soil surrounding water sources and determining and quantifying risk factors associated with their presence.

This study was designed to determine and quantify risk factors associated with the likelihood of detecting Cryptosporidium spp. oocysts or Giardia spp. cysts in the soil of dairy farms in the Catskill region of southeastern New York State.

\section{MATERIALS AND METHODS}

\section{Study Population}

The target population of this study was all dairy farms in southeastern New York State. The farms enrolled in this study had agreed to participate in an agricultural development program, whose goal was to maintain the quality of the water and sustain the economic viability of agriculture in the watershed in that area. At the time of the study, 40 farms agreed to participate in the program, 37 of which we visited.

\section{Determination of Sampling Site and Soil Sample Collection}

A detailed description of sampling site selection and sample collection was provided elsewhere (Barwick and
Mohammed, 1997). Briefly, a multidimensional scale was used to identify sampling sites. This scale consisted of elements that are known or perceived by experts to be associated with the likelihood of the presence of Cryptosporidium spp. or Giardia spp. in these sites. Criteria included in this scale included information about potential contamination sources, such as young stock, proximity to those perceived contamination sources, animal density, and geography of the area. This scale allowed us to apply a numerical level of contamination risk to a geographical area. Only one observer scored each risk area on a farm to reduce interobserver variability. Scores were standardized to control for intraobserver variability from farm to farm.

Once this scale was applied, we were able to characterize these areas into high, moderate, and low likelihood zones. Zones were categorized according to their score as follows: $74 \geq$ high likelihood zone $>45 ; 45 \geq$ moderate likelihood zone $>15$; and low likelihood zone $\leq 15$. The highest likelihood zone was identified as the sampling area for that farm.

Dairy farms enrolled in the study were visited to collect soil samples and to administer a questionnaire to farm owners. Soil samples were collected by inserting a 3 -in diameter stainless steel ring to a depth of 2 in at selected sampling sites. The ring was pushed into the ground and the sample was placed in a sealable plastic bag and properly labeled. Samples were transported back to Cornell University for parasite, $\mathrm{pH}$, and percent moisture content analysis. At the time of the farm visit, the farm owner was interviewed, and data on the hypothesized risk factors were collected using a questionnaire. These factors included information on the sampling site, farm demographics, and management practices and are listed in Table 1.

\section{Sample Analysis}

The soil samples were analyzed individually for the presence of Giardia and Cryptosporidium, $\mathrm{pH}$, and moisture content. Detailed descriptions of these analyses are provided elsewhere (Roach et al., 1991; Rose et al.,1991). Briefly, samples were analyzed microscopically for the presence of Giardia and Cryptosporidium using an adaptation to the flotation procedure used for detection of these organisms in fecal samples (Rose et al., 1991). One observer examined all slides, and all Giardia and Cryptosporidium suspects were confirmed by at least one additional trained reader. The $\mathrm{pH}$ of the soil samples was determined in the laboratory. The $\mathrm{pH}$ was determined with a $\mathrm{pH}$ meter using an equal soilto-water ratio and was measured at room temperature. Gravimetric percent moisture was determined after large rocks had been removed. Ten grams of the sample 
Table 1. Factors evaluated for an association with Cryptosporidium spp. oocysts or Giardia spp. cysts.

\begin{tabular}{ll}
\hline Factor & Description \\
\hline Date of sample collection & Nominal: month \\
Farm area & Nominal: river valley, mountainous, etc. \\
Size of farm & Continuous: measured in acres \\
Number of cattle on farm & Continuous: total number \\
Cattle 6 mo of age & Continuous: total number \\
Potential source of contamination at sampling site & Nominal: calf-holding area, barn cleaner, etc. \\
Size of sampling site & Continuous: measured in square feet \\
Proximity to body of water & Continuous: measured in feet \\
Type of body of water & Nominal: pond, stream, ephemeral \\
Land use & Nominal: drainage, pasture, calf-holding area, agricultural field, not used (etc.) \\
Cattle with access to sampling site & Dichotomous: yes, no \\
Vegetation at sampling site & Nominal: managed grass, weeds and grass, bare soil, brush \\
Prevalence of the parasites in the herd & Continuous \\
Score of multidimensional scale & Nominal: high, moderate, low \\
Slope of the land & Nominal: flat, slight incline, moderate incline, steep \\
Flooding & Dichotomous: unnatural flooding through farm (from pipe break or well, etc.) \\
Depth of sample & Continuous: measured in cm \\
pH & Nominal: acidic, neutral, basic \\
Gravimetric $\%$ moisture content & Continuous \\
\hline
\end{tabular}

was placed on an aluminum pan and placed in a convective oven at $105^{\circ} \mathrm{C}$ for $24 \mathrm{~h}$. The sample was weighed again, and gravimetric percent moisture was determined by a proportion of dry sample to wet sample weight.

\section{Statistical Analysis}

From the data collected during the farm visit, risk factors associated with the likelihood of detection of Cryptosporidium spp. oocysts and Giardia spp. cysts in the farmlands of southeastern New York State were identified using ordinary logistic regression (Dixon, 1992). Our outcome variable was dichotomous, presence or absence of the organism in the sample. Initially, the bivariate association between each factor and the likelihood of detecting the organism was evaluated in a univariate logistic regression model. The logistic regression model used is as follows:

$$
P(\mathrm{D})=\frac{1}{1+\mathrm{e}^{-\left(\alpha+\Sigma \beta_{i} X_{i}\right)}}
$$

where $P(\mathrm{D})$ is the probability of presence of a cyst or oocyst in the sample; $\alpha$ is the log odds of cyst or oocyst in the sample with standard set of factors, and $\beta_{\mathrm{i}}$ is the effect of the respective factor $\mathrm{Xi}$ on the likelihood of detecting the cyst or oocyst in the sample. The significant level of the initial screening was at a $P$ value $\leq 0.10$. The magnitude of the effect of a factor was quantified by the odds ratio (OR). The OR is the odds of recovery of a particular protozoa under the presence of the factor in comparison to the odds of recovery in absence of the factor.
Factors that were significantly associated with the likelihood of the organism in the initial screening were further evaluated jointly in a multivariate analysis. A forward stepping with backwards elimination logistic regression analysis approach was used to identify those variables associated with the risk of detection of $C$. parvum in the soil $(P \leq 0.10)$.

Because the sampling units were clustered by farm, we hypothesized that the clustering might lead to a correlation in the likelihood of these organisms. This hypothesized correlation between samples is due to observed and unobserved farm factors. Conditioning on an observed set of these factors by including them in the logistic regression analysis will sometimes achieve approximate conditional independence. We assumed that the unobserved factors are randomly distributed among farms in the study population, and the significance of this assumption was evaluated using the mixed effect logistic regression analysis (Atwill et al., 1995). The mixed effect model was specified as follows:

$$
P\left(\mathrm{D}_{\mathrm{ij}} / \alpha, \beta_{\mathrm{k}}, \sigma\right)=\frac{1}{1+\mathrm{e}^{-\left(\alpha+\Sigma \beta_{k} X_{i j k}+\mu_{i} \sigma\right)}}
$$

where $P\left(\mathrm{D}_{\mathrm{ij}} / \alpha, \beta_{\mathrm{k}}, \sigma\right)$ is the probability of the presence of a cyst or an oocyst in individual sample $j$ located within random effect level $i$ (e.g., farm); $\alpha$ was the natural logarithm of the odds of testing positive under standard circumstances; and $\beta_{\mathrm{k}}$ was the change in the natural logarithm of the odds for developing the disease for a unit change in the risk factor, $X_{\mathrm{k}}$; and $\mu_{\mathrm{i}} \sigma$ was the farm random effect. 
Table 2. Adjusted odds ratios, confidence intervals, regression coefficients, and standard errors for categorical variables significantly associated with likelihood of detection of Cryptosporidium spp. oocysts in a multivariate analysis.

\begin{tabular}{|c|c|c|c|c|}
\hline Significant variable ${ }^{a}$ & $\begin{array}{l}\text { Regression } \\
\text { coefficient }\end{array}$ & $\begin{array}{l}\text { Standard } \\
\text { error }\end{array}$ & $\begin{array}{l}\text { Odds } \\
\text { ratio }\end{array}$ & $90 \% \mathrm{CI}$ \\
\hline \multicolumn{5}{|l|}{ Land use } \\
\hline Not used ${ }^{b}$ & 0 & & 1.00 & \\
\hline Drainage & 0.408 & 0.495 & 1.50 & $0.67-3.4$ \\
\hline Pasture or barnyard & 0.177 & 0.436 & 1.19 & $0.58-2.5$ \\
\hline Calf holding area & -0.427 & 0.835 & 0.652 & $0.17-2.6$ \\
\hline Area of a barn cleaner & 0.900 & 0.412 & 2.46 & $1.3-4.9$ \\
\hline Agricultural field & 1.39 & 0.543 & 4.01 & $1.6-9.8$ \\
\hline \multicolumn{5}{|l|}{$\mathrm{pH}$} \\
\hline Acidic $^{\mathrm{b}}$ & & & 1.00 & \\
\hline Neutral & -0.626 & 0.262 & 0.535 & $0.35-0.82$ \\
\hline Basic & -1.06 & 0.312 & 0.345 & $0.21-0.58$ \\
\hline \multicolumn{5}{|l|}{ Multidimensional scale } \\
\hline Low $^{b}$ & & & 1.00 & \\
\hline Moderate & 1.33 & 0.573 & 3.76 & $1.5-9.7$ \\
\hline High & 2.45 & 1.01 & 11.6 & $2.2-61.0$ \\
\hline Size of sampling site & -0.0149 & 0.00528 & 0.99 & $0.98-0.99$ \\
\hline$(\text { Size of sampling site })^{2}$ & 0.000052 & 0.000019 & 1.00 & $1.00-1.00$ \\
\hline
\end{tabular}

\section{RESULTS}

A total of 782 soil samples were collected from 37 farms throughout southeastern New York State. We examined risk factors including information on the farm, the management practices of the farm, and particular specifics of the sampling site (Table 1).

\section{Cryptosporidium spp.}

Risk factors were identified to be associated $(P \leq 0.10)$ in a multivariate analysis with the risk of detecting Cryptosporidium spp. in the soil. Categorical factors, their adjusted OR, and corresponding 90\% confidence intervals are listed in Table 2.

Of the different land uses, sites that were in the area of a barn cleaner equipment or used for agricultural purposes were associated with increased likelihood of detecting Cryptosporidium spp. compared with land that did not have a specific use. Samples collected from agricultural fields were four times more likely to have Cryptosporidium spp. in samples collected from agricultural fields (farming fields) in comparison to samples from land with no specific use. There was also a significant association between the $\mathrm{pH}$ of the soil and the likelihood of detecting an oocyst. It was less likely to detect Cryptosporidium spp. oocysts in neutral ( $\mathrm{pH} 6.5$ to 7.5) or basic (pH 7.6 to 9.75) samples in comparison to acidic (pH 3.7 to 6.4 ) samples. There was a significant association between the multidimensional scale and the likelihood of detecting an oocyst. It was more likely to detect an oocyst in samples collected from the moderate risk category $(45 \geq$ score $>15)$ in comparison to those in the low risk category (score $\leq 15$ ). Samples collected from high-risk categories (score $>45$ ) had an even greater likelihood of detecting an oocyst, with an adjusted odds ratio of 11.6 .

There was a significant association between the size of the sampling site and the risk of detection of Cryptosporidium spp. oocysts. The risk decreased as the size of the zone increased, reached the minimum value at $190 \mathrm{sq} \mathrm{ft}$, and then increased (Table 2). There was no significant clustering in the likelihood of detecting Cryptosporidium spp. by farm, as determined by the mixed effect model.

\section{Giardia spp.}

Factors significantly associated with the likelihood of detecting a Giardia spp. cyst in the univariate model are listed in Table 3. The likelihood of detecting Giardia cysts in the soil samples increased with the prevalence of the organism in the herd. There was also a 5.24 times greater likelihood of detecting Giardia in the soil when cattle had access to the sampling site compared with sites where cattle did not have access. Vegetation at the sampling site was significantly associated with the risk of detecting Giardia in the soil. Areas that were brush or bare soil were less likely to test positive for Giardia than land that had managed grass. Managed grass sites were managed or less weedy that areas which were categorized as weeds and grass. These sites were not managed or had spontaneous growth.

The likelihood of detecting Giardia cysts increase significantly at a linear rate of 0.0277 for each percentage 
Table 3. Categorical and continuous variables significantly associated with likelihood of detection of Giardia spp. cysts in univariate analysis.

\begin{tabular}{|c|c|c|c|c|}
\hline Significant variable ${ }^{a}$ & $\begin{array}{l}\text { Regression } \\
\text { coefficient }\end{array}$ & $\begin{array}{l}\text { Standard } \\
\text { error }\end{array}$ & $\begin{array}{l}\text { Odds } \\
\text { ratio }\end{array}$ & $90 \% \mathrm{CI}$ \\
\hline \multicolumn{5}{|l|}{ Area of land } \\
\hline River valley & & & 1.00 & \\
\hline Mountainous region & 1.217 & 0.574 & 3.38 & $1.3-8.7$ \\
\hline Suburban area & -0.920 & 0.873 & 0.398 & $0.095-1.7$ \\
\hline Flatland & 0.117 & 0.621 & 1.12 & $0.40-3.1$ \\
\hline \multicolumn{5}{|l|}{ Acreage of farmland } \\
\hline 161 areas $^{b}$ & & & 1.00 & \\
\hline 162 to 232 acres & -2.77 & 1.04 & 0.0625 & $0.011-0.35$ \\
\hline 233 to 320 acres & -1.05 & 0.528 & 0.350 & $0.15-0.84$ \\
\hline 321 to 525 acres & -1.32 & 0.573 & 0.267 & $0.10-0.69$ \\
\hline \multicolumn{5}{|l|}{ Vegetation at sampling site } \\
\hline Managed grass ${ }^{b}$ & & & 1.00 & \\
\hline Weeds and grass & 0.422 & 0.484 & 1.52 & $0.69-3.4$ \\
\hline Brush or bare soil & -1.30 & 0.614 & 0.273 & $0.099-0.75$ \\
\hline \multicolumn{5}{|l|}{ Cattle access } \\
\hline No cattle with access ${ }^{b}$ & & & 1.00 & \\
\hline Cattle with access & 1.66 & 0.423 & 5.24 & $2.6-11.0$ \\
\hline \multicolumn{5}{|l|}{ Herd prevalence of Giardia } \\
\hline 0 to $0.7 \%$ b & & & 1.00 & \\
\hline 7.1 to $14 \%$ & 0.604 & 0.697 & 1.83 & $0.58-5.8$ \\
\hline 14.1 to $18 \%$ & -0.191 & 0.919 & 0.826 & $0.18-3.8$ \\
\hline 18.1 to $39 \%$ & 1.96 & 0.635 & 7.06 & $2.5-20$ \\
\hline Percent moisture content & 0.0277 & 0.0102 & 1.03 & $1.01-1.05$ \\
\hline No. of cattle 6 mo of age & -0.0731 & -0.0310 & 0.930 & $0.88-0.98$ \\
\hline
\end{tabular}

${ }^{\mathrm{a}} P=0.10$.

${ }^{\mathrm{b}}$ Reference category.

of moisture content in the soil (Table 3). Risk of detection of a Giardia cyst decreased significantly at a linear rate of -0.0731 as the number of the cattle on the farm less than 6 mo of age increased (Table 3).

The random effect of the farm was not significantly associated with the likelihood of detecting a Giardia cyst.

\section{DISCUSSION}

Giardia spp. and Cryptosporidium spp. have been implicated in several drinking water outbreaks of giardiasis and cryptosporidiosis, respectively. As waterborne pathogens, one potential route of transmission from the animal to the water system is through the soil (Smith and Rose, 1998). Because both Giardia spp. and Cryptosporidium spp. have a wide range of hosts, their eradication is unlikely, and efforts to prevent water contamination should focus on the control of these pathogens. To date, Cryptosporidium is able to survive most modern drinking water treatments, and until methods are developed to ensure Cryptosporidium-free water, attention should be focused on preventing the oocyst from entering the water supply system (Smith and Rose, 1998). Soil could be an important vehicle through which the Cryptosporidium oocyst and Giardia cyst can travel into water sources (Smith and Rose, 1998). To design effective prevention strategies, it is important to develop a base knowledge about the factors that play a role in the transmission and contamination of the water supply system. This study represents a step towards that goal. To our knowledge, there is no published study investigating risk factors associated with the presence of Giardia or Cryptosporidium in the soil of dairy farms. Other studies have identified Cryptosporidium spp. and Giardia spp. in water sources but not in soil (Madore et al., 1987; LeChavallier et al., 1991; Roach et al., 1993), and several studies have looked at risk factors related to these organisms but not in soil.

Our sampling design targeted those areas that were identified by the multidimensional scale to have the highest risk of contaminating the environment on a particular farm (Barwick and Mohammed, 1997). This sampling scheme allowed us to assess high-risk areas quantitatively and systematically and provided a feasible design. Furthermore, it allowed us to weigh the sampling towards a high-risk area and utilize our resources efficiently. It was designed to make inferences about the presence of the organisms and factors associated with them. This scale also allowed us to avoid the problem of multicolinearity. Multicolinearity may develop when correlated variables play a role on the risk of a particular outcome, in our case, detection of an oocyst or cyst. This scale allowed us to examine multiple variables and avoid this problem. 
Samples were evaluated using an adaptation of the flotation technique, and we determined a sample to be positive for Cryptosporidium spp. or Giardia spp. if at least one oocyst or cyst was detected (Atwill et al., 1997; Barwick et al, 2000). Although this procedure does not conclude organism viability, oocysts and cysts were evaluated on size, shape, and internal structure, which have been used to indicate viability (Le Chavallier et al., 1991b). Additionally, this method does not identify species of Cryptosporidium or the source of the organism. The oocysts we observed were found in areas believed to be contaminated by cattle, but it is possible that other animals may have been responsible for shedding the oocysts, such as wildlife or domestic animals with access to the area.

It was previously reported that the prevalences of Giardia spp. and Cryptosporidium spp. in the soil of these dairy farms were found to be 4 and $17 \%$, respectively (Barwick and Mohammed, 1997). In these herds, the prevalence of Giardia was as high as $39 \%$ (Wade et al., 2000); thus, it was unexpected that the prevalence of Giardia in the soil would be low. This might be explained by the fact that Giardia is not as resistant to environmental pressures as Cryptosporidium and may not be able to survive for long periods (Rings and Rings, 1996).

In the multivariate analysis, three categorical factors were found to be significantly associated with the likelihood of detecting Cryptosporidium spp. in the soil. The use of the land was significantly associated with the risk of detecting Cryptosporidium spp. oocysts in the soil. The finding that area around barn cleaners and agricultural fields had an increased risk for detecting oocyst compared with land that was not used was consistent with expectations. One would expect that these areas may have large concentrations of manure, particularly when the agricultural field has been spread with fresh manure. We were not able to demonstrate significant association between the prevalence of Cryptosporidium spp. in the animals on the farm and the likelihood of detecting the organism in the soil. One plausible explanation is that the animal sampling was from the animals directly, whereas the soil sampling is cumulative sampling.

The $\mathrm{pH}$ of the soil was significantly associated with the likelihood of detecting Cryptosporidium spp. The risk of detecting the oocyst decreased with increasing levels of $\mathrm{pH}$ (Table 2). Samples in the neutral category ( $\mathrm{pH} 6.5$ to 7.5) were 0.53 times less likely to have a Cryptosporidium oocyst, and those in the basic category ( $\mathrm{pH} 7.6$ to 9.75) were 0.35 times less likely, compared with those samples in the acidic category $(\mathrm{pH} 3.7$ to 6.4). This finding is not consistent with what is reported in the literature (Robertson et al., 1992; Brown et al.,
1996). Interestingly, other studies have shown Cryptosporidium oocysts unable to survive low extremes of pH (Robertson et al., 1992; Brown et al., 1996).

The continuous variables for sampling site size were linearly and nonlinearly associated with the detection of Cryptosporidium spp. in the soil. It appeared as though as the size of the sampling site increased, risk of detection decreased and then began to increase when the sampling site was above $190 \mathrm{sq} \mathrm{ft}$. It is possible that this association is due to the use of the land site or may serve as a proxy for an unmeasured variable relating to the size of the sampling site.

The random effect variable was not significant in this final model. This can be interpreted that the three factors included in this final model account for all the variability in the presence of the oocyst in the soil, or we did not have much variability among our samples.

Several factors were significantly associated with the likelihood of detecting a Giardia cyst in the soil in the univariate analysis. However, none of the factors was significant when we used the multivariate analysis. An obvious explanation is that the prevalence of Giardia in our samples was relatively low, and as a consequence, we were not able to evaluate two factors jointly. The strongest association existed between detection of a cyst and the prevalence of Giardia in the herd. The prevalence of Giardia infection in the herd was obtained through a prevalence study (Wade et al., 2000), and we found that farms that had a prevalence rate of 18 to $39 \%$ were seven times more likely to have soil that tested positive. This is not surprising and supports the conclusion that the cattle were the source of the cysts identified. Whether or not the cattle had access to the area was also strongly associated with the detection of a cyst. Areas that cattle could access were 5.24 times more likely to contain Giardia cysts than those areas to which cattle did not have access. Again, this finding is not surprising in that although Giardia cysts are commonly shed by young stock, it has been found in animals up to and beyond 6 mo of age (Xaio et al., 1993; Xaio and Herd, 1994; Olson et al., 1997). One significant variable that was surprising was the number of cattle $<6$ months of age. This was negatively associated with the risk of detecting a Giardia cyst in the soil. That is, as the number of cattle on the farm $<6$ mo of age increased, the likelihood of detecting a Giardia cyst decreased. This was unexpected, as it is generally the younger animals that tend to be more likely to shed Giardia (Xaio and Herd, 1994; Olson et al., 1997). Another factor significantly associated with detecting a Giardia cyst was the vegetation of the sampling site. Land covered with brush or bare soil was 0.273 less likely to have cysts than land with managed grass. It is possible this is because areas without vegetation 
allow for easier runoff, decreasing the likelihood Giardia would be found there. Also, land with vegetation decreases the rate of evaporation, and soil will stay wet longer, and it has been suggested that Giardia concentrations are higher in wetter soil ( $\mathrm{Hu}$ et al., 1996). More evidence that soil water content plays a role in detecting Giardia was the significance of percent moisture content of the soil. We found that as the percent moisture content increased, the likelihood of detecting a cyst increased also. This agrees with findings by Hu et. al. (1996), who investigated the role of Giardia in sludge mixed with soil. They found that Giardia concentrations decreased in sludge mixed with soil, and they felt this was primarily due to low-moisture content. Another plausible explanation for the absence of Giardia from soil collected from bare or brush areas could be attributed to low grazing intensity and hence, less likelihood of fecal excretion.

As part of our analysis, we included the random effect of the farm into our model to examine for any presence of intragroup correlation among the farms. For both Cryptosporidium and Giardia, it was interesting that the effect of the farm was not significant. For the model based on the risk of detecting Cryptosporidium spp., this may be because there was a fairly high farm prevalence, with $92 \%$ of the farms testing positive for Cryptosporidium spp. (Barwick and Mohammed, 1997).

In conclusion, we found that land use and $\mathrm{pH}$ were associated with the risk of detecting Cryptosporidium spp. in the soil. Herd prevalence, vegetation, moisture content, and cattle access were significantly associated with the likelihood of detecting Giardia spp. in the soil. Future research should be conducted to fully understand the roles these factors play on the existence of these parasites in the soil and help to implement practices which could help to reduce the transmission of these two organisms.

\section{REFERENCES}

Anderson, B. C. 1991. Prevalence of Cryptosporidium muris-like oocysts among cattle populations of the United States: Preliminary report. J. Protozool. 38:14S-15S.

Atwill, E. R., H. O. Mohammed, J. M. Scarlett, and C. E. McCulloch. 1995. Extending the interpretation and utility of mixed effects logistic regression models. Prev. Vet. Med. 24:187-201.

Atwill, E. R., R. A. Sweitzer, M. C. Pereira, I. A. Gardner, D. Van Vuren, and W. M. Boyce. 1997. Prevalence of and associated risk factors for shedding Cryptosporidium parvum oocyst and Giardia cysts within feral pig populations in California. Appl. Environ. Microbiol. 63:3946-3949.

Barwick, R. S., and H. O. Mohammed. 1997. Risk factors associated with the detection of Cryptosporidium parvum in soil samples. Proc. 8th Intl. Symp. Vet. Epi. Econ., Paris.

Barwick, R. S., H. O. Mohammed, M. E. White, and R. B. Bryant. 2000. Detection of Cryptosporidium muris and Cryptosporidium parvum in soil samples. Biol. Fertil. Soils 31:385-390.

Brown, S. M. A., V. McDonald, H. Denton, and G. H. Coombs. 1996. The use of a new viability assay to determine the susceptibility of Cryptosporidium and Eimeria sporozoites to respiratory inhibitors and extremes of pH. FEMS Microbiol. Lett. 142:203-208.

Buret, A., N. denHollander, P. M. Wallis, D. Befus, and M. E. Olson. 1990. Zoonotic potential of giardiasis in domestic ruminants. J. Infect. Dis. 162:231-237.

Dixon, W. J. 1992. BMDP Statistical software. Berkeley, CA: Univ. CA Press.

Fayer, R., and R. G. Leek. 1984. The effects of reducing conditions, medium $\mathrm{pH}$, temperature, and time on in vitro excystation of Cryptosporidium. J. Protozool. 31:567-569.

Fayer, R., and T. Nerad. 1996. Effects of low temperatures on viability of Cryptosporidium parvum oocysts. Appl. Environ. Microbiol. 62:1431-1433.

Fayer, R. 1997. Cryptosporidium and Cryptosporidiosis. CRC Press, Boston, MA.

Garber, L. P., M. D. Salman, H. S. Hurd,T. Keefe, and J. L. Schlater. 1994. Potential risk factors for Cryptosporidium infection in dairy calves. J. Am. Vet. Med. Assoc. 205:86-91.

Goldstein, S. T., D. D. Juranek, O. Ravenholt, A. W. Hightower, D. G. Martin, J. L. Mesnik, S. D. Griffiths, A. J. Bryant, R. R. Reich, and B. L. Herwaldt. 1996. Cryptosporidiosis:an outbreak associated with drinking water despite state-of-the-art water treatment. Ann. Intern. Med. 124:459-468.

Hayes, E. B., T. D. Matte, T. R. O'Brien, T. W. McKinley, G. S. Logsdon, J. B. Rose, B. L. P. Ungar, D. M. Word, P. F. Pinsky, M. L. Cummings, M. A. Wilson, E. G. Long, E. S. Hurwitz, and D. D. Juranek. 1989. Large community outbreak of cryptosporidiosis due to contamination of a filtered public water supply. New England J. Med. 320:1372-1376.

Hu, C. J., R. A. Gibbs, N. R. Mort, H. T. Hofstede, G. E. Ho, and I. Unkovich. 1996. Giardia and its implications for sludge disposal. Wat. Sci. Tech. 34:179-186.

Johnson, E., E. R. Atwill, M. E. Filkinand, and J. Kalush. 1997. The prevalence of shedding of Cryptosporidium and Giardia spp. based on a single fecal sample collection from each of 91 horses used for backcountry recreation. J. Vet. Diagn. Invest. 9:56-60.

Joseph, C., G. Hamilton, M. O'Connor, S. Nicholas, R. Marshall, R. Stanwell-Smith, R. Sims, E. Ndawula, D. Casemore, P. Gallagher, and P. Harnett. 1991. Cryptosporidiosis in the Isle of Thanet; an outbreak associated with local drinking water. Epidemiol. Infect. 107:509-519.

LeChavallier, M. W., W. D. Norton, and R. G. Lee. 1991. Occurrence of Giardia and Cryptosporidium spp. in surface water supplies. Appl. Environ. Microbiol. 57:2610-2616.

Leland, D., J. McAnnult, W. Keene, and G. Stevens. 1993. A cryptosporidiosis outbreak in a filtered water supply. J. Am. Waterworks Assoc. 85:34-42.

MacKenzie, W. R., W. L. Schell, K. A. Blair, D. G. Addiss, D. E. Peterson, N. J. Hoxie, J. J. Kazmierczak, and J. P. Davis. 1995. Massive outbreak of waterborne Cryptosporidium infection in Milwaukee, Wisconsin: Recurrence of illness and risk of secondary transmission. Clin. Infect. Dis. 21:57-62.

Madore, M. S., J. B. Rose, C. P. Gerba, M. J. Arrowood, and C. R. Sterling. 1987. Occurrence of Cryptosporidium oocysts in sewage effluents and selected surface waters. J. Parasit. 73:702-705.

Mawdsley, J. L., A. E. Brooks, and R. J. Merry. 1996. Movement of the protozoan pathogen Cryptosporidium parvum through three contrasting soil types. Biol. Fertil. Soils 21:30-36.

Moore, D. A., and D. H. Zeman. 1991. Cryptosporidiosis in neonatal calves: 277 cases (1986-1987). J. Am. Vet. Med. Assoc. 198:1969-1971.

Mtambo, M. M. A., A. S. Nash, D. A. Blewett, H. V. Smith, and S. Wright. 1991. Cryptosporidium infection in cats: prevalence of infection in domestic and feral cats in the Glasgow area. Vet. Rec. 129:502-504.

Muriuki, S. M. K., I. O. Farah, R. M. Kagwiria, D. C. Chai, G. Njamunge, M. Suleman, and J. O. Olobo. 1997. The presence of Cryptosporidium oocysts in stools of clinically diarrhoeic and normal nonhuman primates in Kenya. Vet. Parasitol. 72:141-147.

Olson, M. E., C. L. Thorlakson, L. Deselliers, D. W. Morck, and T. A. McAllister. 1997. Giardia and Cryptosporidium in Canadian farm animals. Vet. Parasitol. 68:375-381. 
Richardson, A. J., R. A. Frankenberg, A. C. Buck, J. B. Selkon, J. S. Colbourne, J. W. Parsons, and R. T. Mayon-White. 1991. An outbreak of waterborne cryptosporidiosis in Swindon and Oxfordshire. Epidemiol. Infect. 107:485-495.

Rings, D. M., and M. B. Rings. 1996. Managing Cryptosporidium and Giardia infections in domestic ruminants. Vet. Med. 91:11251131.

Roach, P. D., M. E. Olson, G. Whitley, and P. M. Wallis. Waterborne Giardia cysts and Cryptosporidium oocysts in the Yukon, Canada. Appl. Environ. Microbiol. 59:67-73.

Robertson, L. J., A. T. Campbell, and H. V. Smith. 1992. Survival of Cryptosporidium parvum oocysts under various environmental pressures. Appl. Environ. Microbiol. 58:3494-3500.

Rose, J. B., C. P. Gerba, and W. Jakubowski. 1991. Survey of potable water supplies for Cryptosporidium and Giardia. Environ. Sci. Technol. 25:1393-1400.

Schwabe, C. W., H. P. Riemann, and C. W. Franti. 1977. Epidemiology in Veterinary Medicine. Lea and Febiger, Philadelphia, PA.
Smith, H. V., W. J. Patterson, R. Hardie, L. A. Greene, C. Benton, W. Tulloch, R. A. Gilmour, R. W. A. Girdwood, J. C. M. Sharp, and G. I. Forbes. 1989. An outbreak of waterborne cryptosporidiosis caused by post-treatment contamination. Epidem. Inf 103:703-715.

Smith, H. V., and J. B. Rose. 1998. Waterborne cryptosporidiosis: Current status. Parasitol. Today 14:14-22.

Solo-Gabriele, H., and S. Neumeister. 1996. US outbreaks of cryptosporidiosis. J. Am. WaterWorks Assoc. 88:76-86.

Wade, S., and H. O. Mohammed. 2000. Prevalence of Giardia and Cryptosporidium spp. in dairy cattle in New York State watershed. Vet. Parasitol. 93:1-11.

Xiao, L., R. P. Herd, and D. M. Rings. 1993. Diagnosis of Cryptosporidium on a sheep farm with neonatal diarrhea by immunofluorescence assays. Vet. Parasitol. 47:17-23.

Xiao, L., and R. P. Herd. 1994. Infection patterns of Cryptosporidium and Giardia in calves. Vet. Parasitol. 55:257-262. 